\title{
Effect of mean ocular perfusion pressure on primary open angle glaucoma
}

\author{
Pallab Kumar Sen, Nazneen Khan and Md. Shafiqul Islam
}

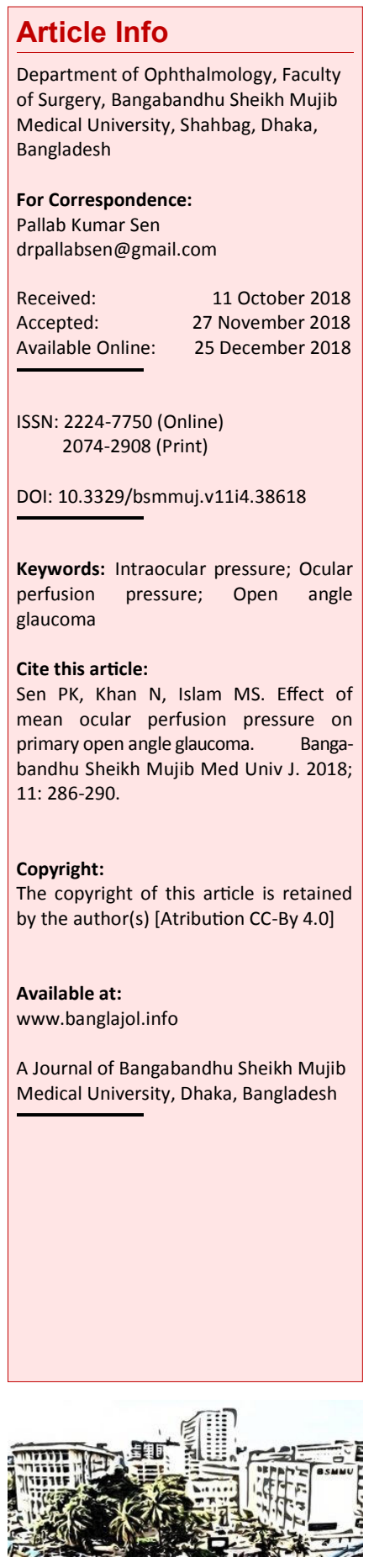

\section{Abstract}

Primary open angle glaucoma is the most common form of glaucoma and it remains asymptomatic until the late stage of the disease. The purpose of this study is to compare the mean ocular perfusion pressure with the primary open angle glaucoma. A total of 60 study subjects were divided into two following groups: a) newly diagnosed patients with primary open angle glaucoma (case) and b) age and sex-matched healthy volunteers (control). The intraocular pressure and blood pressure were measured 3 hourly from 8:00 am to 11:00 pm. The mean ocular perfusion pressure of the right eyes in untreated primary open angle glaucoma was $39.9 \pm 7.5 \mathrm{~mm} \mathrm{Hg}$ whereas it was $47.7 \pm 7.7 \mathrm{~mm} \mathrm{Hg}$ in the control. The odds ratio was 6.6 (95\% CI, 2.1-20.5; $\mathrm{p}=0.002$ ). The right eyes of untreated primary open angle glaucoma had 6.6 times more risk compared to the control group. The mean ocular perfusion pressure of left eyes in untreated primary open angle glaucoma was $39.9 \pm 7.5 \mathrm{~mm} \mathrm{Hg}$ and $48.6 \pm 4.0 \mathrm{~mm} \mathrm{Hg}$ in the control group. The odds ratio was 5.7 $(95 \% \mathrm{CI}, 1.8-17.5 ; \mathrm{p}=0.004)$. The left eyes of untreated primary open angle glaucoma had 5.7 times more risk compared to control group. The findings revealed the evidence of vascular mechanism in glaucoma pathogenesis: Reduction of mean ocular perfusion pressure $\leq 48 \mathrm{~mm} \mathrm{Hg}$, may lead to daily repetitive ischemic insult to the optic nerve.

\section{Introduction}

Glaucoma is a multifactorial disease characterized by a loss of retinal ganglion cells that leads to typical damage of the optic nerve and visual field. Although intraocular pressure is considered the main risk factor for the development of glaucoma and the only parameter subject to treatment but glaucoma continues to progress despite lowering patient's intraocular pressure to targeted level.1 The number of people with primary glaucoma in the world by the year 2000 is estimated at nearly 66.8 million, with 6.7 million suffering from bilateral blindness.2,3 Glaucoma blindness ranking only second to cataract (19.3 million) as a cause of blindness worldwide. 4 Approximately $70 \%$ of glaucoma is found in developing countries and estimated that two-thirds of those blind are cases of primary open angle glaucoma.5 Primary open angle glaucoma is more common than PACG in Indo-Aryan.6 It is estimated that there are approximately 586000 people of 40 years and older with definite or probable glaucoma in Bangladesh.7The intraocular pressure refers to the pressure exerted by intraocular contents on the coats of the eyeball. The normal level of intraocular pressure is essentially maintained by a dynamic equilibrium between the aqueous humor formation, aqueous humor outflow and episcleral venous pressure. Perfusion pressure is the difference between arterial and venous pressure. In the eye, venous pressure is equal to or slightly higher than intraocular pressure. 8 Ocular perfusion pressure can be further broken down into diastolic perfusion pressure (diastolic blood pressure minus intraocular pressure) and systolic perfusion pressure (systolic blood pressure minus intraocular pressure). Hence, ocular perfusion pressure can be decreased by raising the intraocular pressure or reducing blood pressure. Poor perfusion of tissues can occur in the context of either hypertension or hypotension. Hypertension works by increasing peripheral vascular resistance in small vessels, while hypotension works by producing insufficient perfusion pressure of the optic disc. Treatment or overtreatment of systemic hypertension may cause a marked decrease in systemic blood pressure this, in turn, causes decrease in systolic and diastolic perfusion pressure leading to chronic decrease of ocular blood flow, ultimately loss of retinal ganglion cells. 9 Blood flow in any tissue is generated by the perfusion pressure that is defined as the difference between mean arterial blood pressure and venous pressure.10 In the resting position, mean arterial blood pressure is calculated as: $\mathrm{MAP}=\mathrm{DBP}+1 / 3(\mathrm{SBP}-\mathrm{DBP})$. 
It is established that the venous pressure should be marginally higher than the intraocular pressure, to allow for adequate blood circulation. $\underline{10,11}$ To calculate the mean ocular perfusion pressure, intraocular pressure is substituted for venous pressure. So, the mean ocular perfusion pressure in the eye is equal to the difference between the $2 / 3$ of mean arterial blood pressure and intraocular pressure. $\underline{12}$

Diurnal variation of intraocular pressure is well documented and it has been demonstrated that the range of intraocular pressure variation is larger in persons with primary open angle glaucoma than normal.13, 14 The perfusion pressure changes during the day, but the tissue blood flow should remain stable to maintain adequate metabolic activity. $\underline{15}$ The higher the intraocular pressure, the larger the range of diurnal variation and that diurnal variation in intraocular pressure is not an independent risk factor for the development of glaucoma. However, mean intraocular pressure was found to be a strong risk factor. $\underline{16}$ There are very few studies regarding the effect of mean ocular perfusion pressure and its role as a risk factor for primary open angle glaucoma. $\underline{17}$

\section{Materials and Methods}

This study was carried out from January 2011 to June 2012. Considering the inclusion and exclusion criteria, 60 study subjects were selected of which 30 were newly diagnosed untreated primary open angle glaucoma (Group A) and 30 were age and sex -matched healthy volunteers (Group B). Inclusion criteria for case individuals were a) Patients having primary open angle glaucoma only without any other ocular pathology; b) Age -35 years and above; c) Patients from both sexes; d) Intraocular pressure more than $21 \mathrm{~mm} \mathrm{Hg}$, recorded in any time; and e) Newly diagnosed patients as primary open angle glaucoma but not started treatment. The inclusion criteria for control individuals were a) Age and sex-

\begin{tabular}{|c|c|c|c|}
\hline \multicolumn{4}{|c|}{ Table I } \\
\hline \multicolumn{4}{|c|}{ Age and sex distribution of study subjects } \\
\hline & $\begin{array}{c}\text { Group A } \\
(\mathrm{n}=30)\end{array}$ & $\begin{array}{c}\text { Group B } \\
(\mathrm{n}=30)\end{array}$ & \multirow[t]{2}{*}{$\mathrm{p}$ value } \\
\hline & No. & No. & \\
\hline \multicolumn{4}{|l|}{ Age (in years) } \\
\hline $35-44$ & 3 & 3 & \multirow[t]{5}{*}{0.983} \\
\hline $45-54$ & 9 & 8 & \\
\hline $55-64$ & 6 & 7 & \\
\hline $65-74$ & 9 & 10 & \\
\hline 75 and above & 3 & 2 & \\
\hline Mean age \pm SD & $59.2 \pm 2.2$ & $58.9 \pm 2.0$ & \\
\hline \multicolumn{4}{|l|}{ Sex } \\
\hline Male & 26 & 26 & \multirow[t]{2}{*}{0.647} \\
\hline Female & 4 & 4 & \\
\hline
\end{tabular}

matched (with the case group); b) No history of ocular diseases affecting intraocular pressure; c) No history of ocular surgery; d) No family history of primary open angle glaucoma; and e) At present free from any eye disease.

The detailed history was taken from all the selected study subjects, which then underwent a detailed clinical examination. Demographic and clinical data of the study population were noted in a predesigned datasheet. Intraocular pressure was measured with Goldmann applanation tonometer (Haag-Streit, Germany), 3 hourly, from 8:00 am to 11:00 pm of admitted study subjects under admission. To ensure the quality of data of every study subject was crosschecked by the supervisors. The resting blood pressure was also recorded at the same time, in the left arm. The measured blood pressure and intraocular pressure were recorded in the data sheet. From systolic blood pressure, diastolic blood pressure, intraocular pressure, ocular perfusion pressure were calculated in both the case and control groups. The mean ocular perfusion pressure of untreated primary open angle glaucoma was compared with those of the control group by appropriate statistical analysis.

Blood flow in any tissue is generated by the perfusion pressure that is defined as the difference between mean arterial blood pressure and venous pressure. 10

It is established that the venous pressure should be marginally higher than the intraocular pressure, to allow for adequate blood circulation. $.10,11$ To calculate the mean ocular perfusion pressure, intraocular pressure is substituted for venous pressure. So, the mean ocular perfusion pressure in the eye is equal to the difference between the $2 / 3$ of MAP and intraocular pressure. $\underline{\underline{12}}$

\section{Results}

Table I shows the mean age and the number gender variation were similar.

The mean intraocular pressure and ocular perfusion pressure in both eyes of untreated primary open angle glaucoma were higher than the normal control (Table II). Both the parameters were not changed significantly at different time of the day.

Both systolic and diastolic blood pressure in both groups were within normal range (data not shown).

Table III shows the odds ratio for right eye was 6.6 (95\% CI, 2.1-20.5, $\mathrm{p}=0.002)$ and for left eye was 5.7 (95\% CI, 1.8-17.5, p=0.004) when cut off value of mean ocular perfusion pressure was $46 \mathrm{~mm} \mathrm{Hg}$. The right eye of untreated primary open angle glaucoma had 6.6 times more risk compared to the control group. It was statistically significant $(p=0.002)$. The 


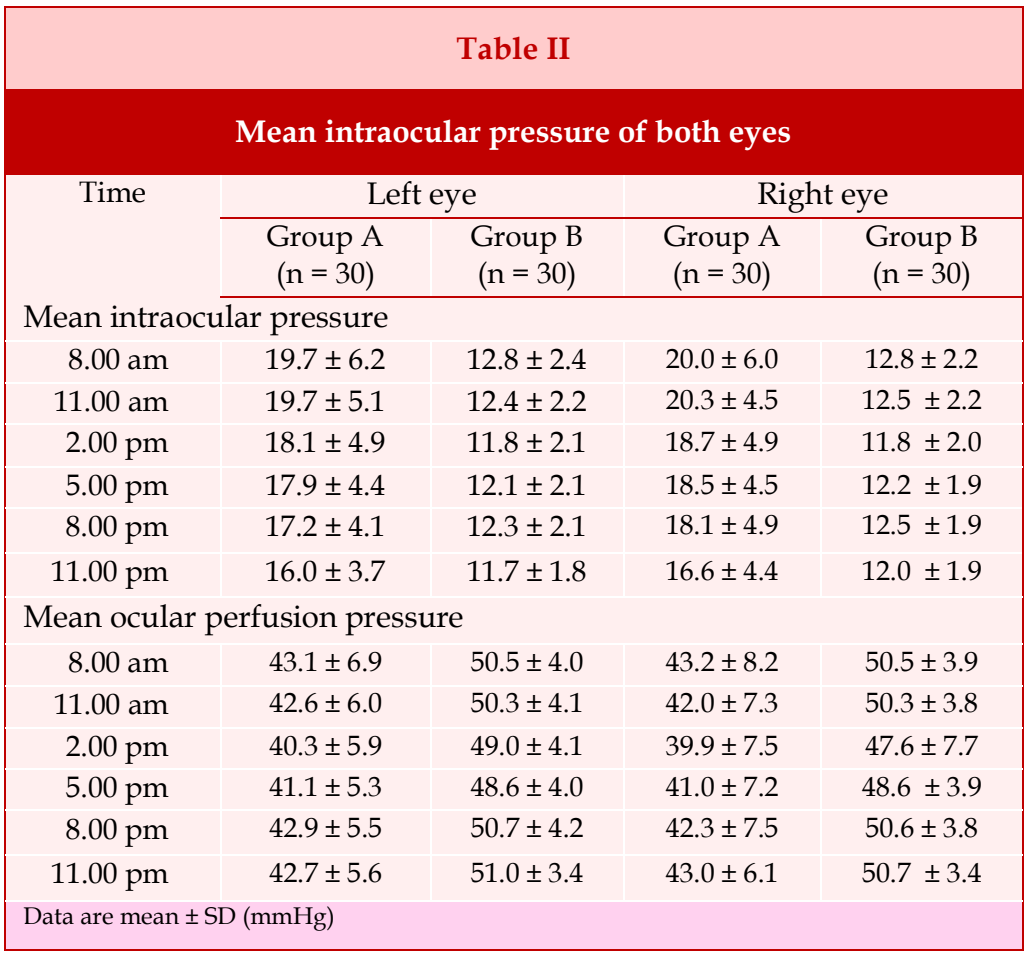

Table III

Odds ratio of untreated primary open angle glaucoma study subjects for ocular perfusion pressure of both eyes in both groups Measurement Cut off value $46 \mathrm{mmHg}$ Cut off value $48 \mathrm{mmHg}$,

\begin{tabular}{|lccccccc|} 
& Odds & $95 \% \mathrm{CI}$ & $\begin{array}{c}\mathrm{p} \\
\text { value }\end{array}$ & $\begin{array}{l}\text { Odds } \\
\text { ratio }\end{array}$ & $95 \% \mathrm{CI}$ & $\begin{array}{c}\mathrm{p} \\
\text { value }\end{array}$ \\
\hline $\begin{array}{l}\text { Mean ocular perfusion } \\
\text { pressure, right eye }\end{array}$ & 6.6 & $2.1-20.5$ & 0.002 & 6.6 & $2.1-20.5$ & 0.002 \\
$\begin{array}{l}\text { Mean ocular perfusion } \\
\text { pressure, left eye }\end{array}$ & 5.7 & $1.8-17.5$ & 0.004 & 5.2 & $1.7-16.5$ & 0.007 \\
\hline
\end{tabular}

left eye of untreated primary open angle glaucoma had 5.7 times more risk compared to the control group. It was statistically significant $(\mathrm{p}=0.004)$.

The odds ratio for right eye was $6.6(95 \% \mathrm{CI}, 2.1$ 20.5, $\mathrm{p}=0.002)$ and for left eye was $5.2(95 \% \mathrm{CI}, 1.7$ $16.5, p=0.007)$ when the cut off value of mean ocular perfusion pressure was assumed $48 \mathrm{~mm} \mathrm{Hg}$. The right eye of untreated primary open angle glaucoma had 6.6 times more risk compared to the control group. It was statistically significant $(\mathrm{p}=0.002)$.

The left eye of untreated primary open angle glaucoma had 5.2 times more risk compared to the control group. It was statistically significant $(\mathrm{p}=0.007)$.

\section{Discussion}

It has already been established that measurement of blood pressure in a single session may give the potential variability of blood pressure and the impact of "white coat syndrome" having a single elevated blood pressure reading may not represent the status of true blood pressure.18 Diurnal variation of intraocular pressure is an well-known phenomenon in primary open angle glaucoma, single measurement of intraocular pressure may have been subject to measurement error. 19 In this study, instead of a single time point measurement we measure blood pressure, intraocular pressure and calculated mean ocular perfusion pressure, 3 hourly, from 8:00 am to 11:00 pm. The value of single time-point measurement of perfusion pressure in clinical settings is uncertain.20 During this study, we found the different presentation in both eyes regarding BCVA, C:D, NRR and intraocular pressure. Intraocular pressure is an important determinant of mean ocular perfusion pressure, so we wanted to explore logically the asymmetric presentation of both eyes in most of the cases and we focused on mean ocular perfusion pressure for the individual eye in every point of time.

Mean intraocular pressure of left eye was found highest at 11:00 am and lowest at 11:00 pm in Group -A. Highest mean intraocular pressure at 8:00 am and lowest mean intraocular pressure at 11:00 pm in Group-B. The differences between the two groups were statistically significant $(p=0.001)$. The mean intraocular pressure of right eye was found highest at 11:00 am and lowest at 11:00 pm in Group A. Highest mean intraocular pressure at 8:00 am and lowest mean intraocular pressure at 2:00 pm in Group B. The differences between the two groups were statistically significant.

In this study, we found the lowest mean ocular perfusion pressure $40.3 \pm 5.9 \mathrm{~mm} \mathrm{Hg}$ at 2:00 pm in Group A and $48.6 \pm 4.0 \mathrm{~mm} \mathrm{Hg}$ at 5:00 pm in Group $\mathrm{B}$, in left eye. We found the lowest mean ocular perfusion pressure $39.9 \pm 7.5 \mathrm{~mm} \mathrm{Hg}$ at 2:00 pm in Group A and $47.6 \pm 7.7 \mathrm{~mm} \mathrm{Hg}$ at 2:00 pm in Group $\mathrm{B}$ of right eye. The differences between the two groups were statistically significant $(\mathrm{p}<0.001)$.

The longitudinal perspective, Beaver Dam Eye Study found an association between low perfusion pressure and open angle glaucoma..21 Low perfusion pressure is more relevant to the development of primary open angle glaucoma than low blood pressure, as low pulse pressure may more closely reflect the level of blood flow to the optic nerve head. 19

The odds ratio for right eye was 6.6 (95\% CI, 2.120.5, $\mathrm{p}=0.002)$ and for left eye was $5.7(95 \% \mathrm{CI}, 1.8$ $17.5, p=0.004)$, when cut off value of mean ocular perfusion pressure was $46 \mathrm{~mm} \mathrm{Hg.18}$ The right eye of untreated primary open angle glaucoma in Group A had 6.6 times more risk compared to control group in Group B. The difference was statistically significant $(\mathrm{p}=0.002)$. 
The left eye of untreated primary open angle glaucoma in Group A had 5.7 times more risk compared to control group (Group B). The difference was statistically significant.

When we assumed the cut off value of mean ocular perfusion pressure, $48 \mathrm{~mm} \mathrm{Hg}$, then the odds ratio for right eye was 6.6 (95\% CI, 2.1-20.5, p=0.002) and for left eye was 5.2 (95\% CI, 1.7-16.5, p=0.007). The left eye of untreated primary open angle glaucoma in Group A had 5.2 times more risk compared to control group (Group B). The difference was statistically significant.

The decrease in diurnal mean ocular perfusion pressure was found to be significantly larger in patients with untreated primary open angle glaucoma than in normal subjects. $\underline{22}$

Mean ocular perfusion pressure distinguished patients with untreated primary open angle glaucoma from normal subjects. The assessment of mean ocular perfusion pressure may be a useful clinical tool for the evaluation of early primary open angle glaucoma. We found postprandial significant reduction of mean ocular perfusion pressure in both eyes in untreated primary open angle glaucoma in Group A, which should be considered when evaluating ocular perfusion. The mean ocular perfusion pressure was at its lowest in untreated primary open angle glaucoma at 2:00 pm and intraocular pressure was at its highest at 11:00 am. In another study, it was found postprandial systemic hypotension but not regarding the mean ocular perfusion pressure. 23 In this study, it was found that lowest mean ocular perfusion pressure in primary open angle glaucoma at 2:00 pm was not due to intraocular pressure, it was most probably due to diastolic blood pressure. The effect of periods of reduced ocular perfusion pressure on optic nerve head blood flow remains to be answered. Decreasing the mean ocular perfusion pressure from 48 to $46 \mathrm{~mm} \mathrm{Hg}$, there is increased risk of primary open angle glaucoma from 5.2 to 5.7 in the left eyes, but the risk of right eyes remained higher as 6.6.

\section{Conclusion}

The findings of this study revealed evidence of a vascular mechanism in glaucoma pathogenesis: Reduction of mean ocular perfusion pressure $\leq 48$ $\mathrm{mm} \mathrm{Hg}$, may lead to daily repetitive ischemic insult to the optic nerve. This study suggests that the mean ocular perfusion pressure should be considered when evaluating primary open angle glaucoma.

\section{Ethical Issue}

The study protocol was approved by the Institutional
Review Board. The objectives of the study along with risk and benefits were fully explained to the study subjects and informed written consent was taken from all. The ethical principles of the Helsinki Declaration were followed.

\section{References}

1. Sommer A, Tielsch JM, Katz J. Relationship between intraocular pressure and primary open angle glaucoma among white and black Americans. The Baltimore eye survey. Arch Ophthalmol. 1991; 109: 1090-95.

2. Quigley HA. The number of people with glaucoma worldwide. Br J Ophthalmol. 1996; 80: 389-93.

3. Johnson GJ. Global perspective on blindness. In: Oxford Textbook of ophthalmology. Easty DL, Sparrow JM (eds). New York, Oxford University Press, 1999, pp 956-57.

4. World Health Organization. Vision 2020 priority eye diseases. Geneva, WHO, 2006, pp 1-7.

5. Thylefors B, Negrel AD. The global impact of glaucoma. Bull World Health Organ. 1994; 72: 323-26.

6. Ramakrishna $R$, Nirmalan $P$, Krishnadas $R$, Thulasiraj RD, Tielsch JM, Katz J, Friedman DS, Robin AL. Glaucoma in a rural population of Southern India: The aravind comprehensive eye. Ophthalmology 2003; 110: 1484-90.

7. Rahman MM, Rahman N, Foster PJ, Haque Z, Zaman AU, Dineen B, Johnson GJ. The prevalence of glaucoma in Bangladesh: A population based survey in Dhaka division. Br J Ophthalmol. 2004; 88: 1493-97.

8. Costa VP, Harris A. Diurnal perfusion pressure in Glaucoma patients. Glaucoma Today. 2008; 1: 3134.

9. McMenemy MG. Primary open angle glaucoma. In: The Glaucoma book: A practical, evidence-based approach to patient care. Schacknow PN, Samples JR (eds). USA, Springer Science and Business Media, 2010, p 399-419.

10. Anderson DR. Introductory comments on blood flow autoregulation in the optic nerve head and vascular risk factors in glaucoma. Surv Ophthalmol. 2004; 43: S5-S9.

11. Hayreh SS. Blood flow in the optic nerve head and factors that may influence it. Prog Retin Eye Res. 2001; 20: 595-624.

12. Gherghel D, Orgul S, Gugleta K, Gekkieva M, Flammer J. Relationship between ocular perfusion pressure and retrobulbar blood flow in patients with glaucoma with progressive damage. Am J Ophthalmol. 2000; 130: 597-605.

13. Wilensky JT. The role of diurnal pressure measurements in the management of open angle glaucoma. Curr Opin Ophthalmol. 2004; 15: 90-92. 
14. Sacca SC, Rolando M, Marletta A, Macri A, Cerqueti P, Ciurlo G. Fluctuations of intraocular pressure during the day in open-angle glaucoma, normal-tension glaucoma and normal subjects. Ophthalmologica 1998; 212: 115-19.

15. Pillunat LE, Anderson DR, Knighton RW, Joos KM, Feuer WJ. Autoregulation of human optic nerve head circulation in response to increased intraocular pressure. Exp Eye Res. 1997; 64: 737-44.

16. Heijl A, Leske MC, Bengtsson B, Hyman L, Bengtsson B, Hussein M. Reduction of intraocular pressure and glaucoma progression: Results from the early manifest glaucoma trial. Arch Ophthalmol. 2004; 120: 1268-79.

17. Liu JH, Gokhale PA, Loving RT, Kripke DF, Weinreb RN. Laboratory assessment of diurnal and nocturnal ocular perfusion pressures in humans. J Ocul Pharmacol Ther. 2003; 19: 291-97.

18. Memarzadeh F, Ying-Lai M, Chung J, Azen SP, Varma R. Blood pressure, perfusion pressure and open angle glaucoma: The Los Angeles Latino Eye study. Invest Ophthalmol Vis Sci. 2010; 51: 2872-77.

19. Asrani S. Diurnal variation in IOP. Glaucoma Today. 2003; 1: 1-3.

20. Zheng Y, Wong TY, Mitchell P, Friedman DS, He M, Aung T. Distribution of ocular perfusion pressure and its relationship with open angle glaucoma: The Singapore Malay Eye Study. Invest Ophthalmol Vis Sci. 2010; 51: 3399-404.

21. Klein BEK. Intraocular pressure and systemic blood presure: Longitudinal prospective: The Beaver Dam Eye Study. J Ophthalmol. 2005; 89: 284-87.

22. Choi J, Kim KH, Jeng J, Cho H, Lee CH, Kook MS. Circadian fluctuation of mean ocular perfusion pressure is a constant risk factor for normal tension glaucoma. Invest Ophthalmol Vis Sci. 2007; 48: 10411.

23. Sehi M, Flagnan JG, Zeng L, Cook RJ, Trope GE. Relative change in diurnal mean ocular perfusion pressure: A risk factor for the diagnosis of primary open angle glaucoma. Invect Ophthalmol Visual Sci. 2005; 46: 56167. 